application for this use of dipsticks is bacterial-mycobacterial effusion discrimination, particularly in the setting of resourcelimited healthcare systems. However, where access to standard biochemical pleural fluid analysis, including adenosine deaminase [5], is available, dipstick tests add little value to current practice.

\section{J.M. Porcel*, A. Esquerda" ${ }^{*}$ and S. Bielsa*}

Depts of *Internal Medicine and "Laboratory Medicine, Pleural Diseases Unit, Arnau de Vilanova University Hospital, Unitat de Recerca Biomèdica de Lleida, Lleida, Spain.

Correspondence: J.M. Porcel, Dept of Internal Medicine, Arnau de Vilanova University Hospital, Avda Alcalde Rovira Roure 80, 25198 Lleida, Spain. E-mail: jporcelp@yahoo.es

\section{REFERENCES}

1 Porcel JM, Vives M, Cao G, et al. Biomarkers of infection for the differential diagnosis of pleural effusions. Eur Respir J 2009; 34: 1383-1389.

2 Peeling RW, Mabey D. Point-of-care tests for diagnosing infections in the developing world. Clin Microbiol Infect 2010; 16: 1062-1069.

3 Azoulay E, Fartoukh M, Galliot R, et al. Rapid diagnosis of infectious pleural effusions by use of reagent strips. Clin Infect Dis 2000; 31: 914-919.

4 Castellote J, Lopez C, Gornals J, et al. Use of reagent strips for the rapid diagnosis of spontaneous bacterial empyema. J Clin Gastroenterol 2005; 39: 278-281.

5 Porcel JM, Esquerda A, Bielsa S. Diagnostic performance of adenosine deaminase activity in pleural fluid: a single-center experience with over 2100 consecutive patients. Eur J Intern Med 2010; 21: 419-423.

\title{
Response of automatic continuous positive airway pressure devices in a normal subject
}

\section{To the Editors:}

Obstructive sleep apnoea (OSA) is a prevalent disease whereby people become unable to breathe when asleep. During sleep the pharyngeal walls are sucked in and collapse completely, causing full (termed apnoea) or incomplete (termed hypopnoea) abolition of airflow. OSA can lead to daytime fatigue and sleepiness, impairment in cognitive functions, motor vehicle crashes, hypertension, cardiovascular disease, stroke and premature deaths [1].

OSA is easily treated with continuous positive pressure applied throughout sleep [2]. The right amount of pressure is determined individually during a titration night, when pressure is gradually increased to keep the airway open to allow for normal sleep and breathing [2]. In 1993 it was postulated that this process of titration could be performed with a stand alone blower equipped with a microprocessor guiding the positive pressure [3]. The idea was to use the blower as a monitoring device identifying abnormal breathing events and react by increasing pressure until disappearance of the abnormal events. The device would then slowly decrease pressure until events reappeared and the pressure would then be increased again [3]. These machines, termed automatic continuous positive airway pressure devices (autoCPAP), were proposed as monitoring or even diagnostic machines [4], as devices used for one night to determine the fixed CPAP level to be used thereafter [5] or even as therapeutic machines to be used every night and to adapt the pressure necessary to keep the pharynx open at all times [6].

When autoCPAP devices were tested in a bench study it was shown that no two devices reacted alike, that many devices did not even recognise the events they were supposed to act upon and that even when recognising the events, many were not able to correct them [7].

Contrary to pharmaceutical treatments, autoCPAP devices have never been submitted to phase I studies. In other words, they have never been applied to normal subjects [8]. If the assumptions behind these devices are correct, an autoCPAP applied to a normal subject should detect no abnormality in breathing and therefore its positive pressure should remain at the minimum level $\left(4 \mathrm{cmH}_{2} \mathrm{O}\right.$ in general) necessary to wash out the expired $\mathrm{CO}_{2}$ from the mask. We decided to test this scenario in a double-blind experiment in one normal volunteer.

The volunteer subject was a 29-yr-old never-smoker male with an unremarkable medical history. On medical examination weight was $90.5 \mathrm{~kg}$ and height was $186 \mathrm{~cm}$. Blood pressure was $115 / 75 \mathrm{mmHg}$, heart rate was 63 beats $\cdot \mathrm{min}^{-1}$ and the transcutaneous $\mathrm{O}_{2}$ saturation was $98 \%$. The rest of the physical examination was unremarkable. The Mallampati score was 1.

The subject signed an informed consent form and received a payment of $€ 100$ for each polysomnography (PSG). On two successive nights PSG was recorded. After verifying the normality of sleep and breathing he was given a CPAP machine (Good-Knight 420G device ${ }^{\circledR}$; Covidien, Mansfield, MA, USA) with mask (Flexy Fit407®; Fisher and Paykel, Auckland, New Zealand) and gears to use at home at a pressure of $4 \mathrm{cmH}_{2} \mathrm{O}$. After a few nights habituation, a new PSG was performed. After verifying that the patient could sleep normally with the minimum pressure CPAP the experimental study was started. 
It consisted of pairs of successive nights with full PSG. On one night the subject slept connected to the $4 \mathrm{cmH}_{2} \mathrm{O}$ CPAP device and on the other night to one of the tested autoCPAP devices. The order of the nights was randomised and double-blind. Only one of the authors (P. Delguste) randomised the nights by flipping a coin and connected the volunteer to the CPAP or autoCPAP devices. For all nights the same mask, headgear and tubing were used. During the CPAP nights the same device was used throughout the study.

Full night PSG was recorded and analysed as previously described [9]. Apnoeas, hypopnoeas and flow limitation periods were defined according to the American Academy of Sleep Medicine.

We tested five main brands of autoCPAP devices using their proprietary algorithms. All machines were used according to the manufacturers' instructions with a minimum pressure fixed at $4 \mathrm{cmH}_{2} \mathrm{O}$ and maximal pressure at $15 \mathrm{cmH}_{2} \mathrm{O}$. The devices produced an automatic report the following morning.

The protocol of the study had been approved by the University Hospital Ethics Committee (Belgian Record Number B40320072016).

Table 1 presents the sleep data for the 13 PSGs. The subject was a rather long sleeper, with sleep times $>9 \mathrm{~h}$, sleep efficiencies $>80 \%$, very little wake time after sleep onset and normal proportions of sleep stages. For the first PSG, we observed eight hypopnoeas, one central and one obstructive apnoea, all in stage two non-rapid eye movement (NREM) sleep and seven episodes of flow limitation (two in stage two NREM sleep and the other five in rapid eye movement (REM) sleep) with a length between 20 and $60 \mathrm{~s}$. The second diagnostic PSG showed 11 hypopnoeas, three obstructive and two central apnoeas, all in REM sleep. There were three episodes of flow limitation with lengths from 30 to $120 \mathrm{~s}$ in REM sleep. There was no snoring observed. The first PSG under $4 \mathrm{cmH}_{2} \mathrm{O}$ CPAP did not show major modifications in sleep parameters, except a slight reduction in stage three to four NREM sleep and a slight increase in stage two NREM sleep (table 1).

The following recordings on CPAP or autoCPAP showed similar patterns of sleep without any major change in sleep length, efficiency, latency, fragmentation, stage proportions or any other characteristic.

All autoCPAP devices increased pressure during the night, from three to 14 times and remained above baseline for lengths varying from 87 to $312 \mathrm{~min}$, corresponding to $15-83 \%$ of total sleep time. Maximal pressures varied between 6 and $8 \mathrm{cmH}_{2} \mathrm{O}$. There was a great difference between the devices for the number of increases, the elapsed time before returning to baseline pressure and the maximal pressure attained. Figure 1 shows all the hypnograms and the corresponding pressure traces throughout the night for the third recording and all the autoCPAP nights.

We examined each instance of increase in pressure to identify possible reasons for the pressure increases. Pressure could increase in wakefulness after a body position change, after a central apnoea, coincident with expiratory snoring, after a movement arousal, after a long expiratory pause $(\leqslant 10 \mathrm{~s})$, during a period of flow limitation or most frequently without any identifiable reason (see online supplementary figure).

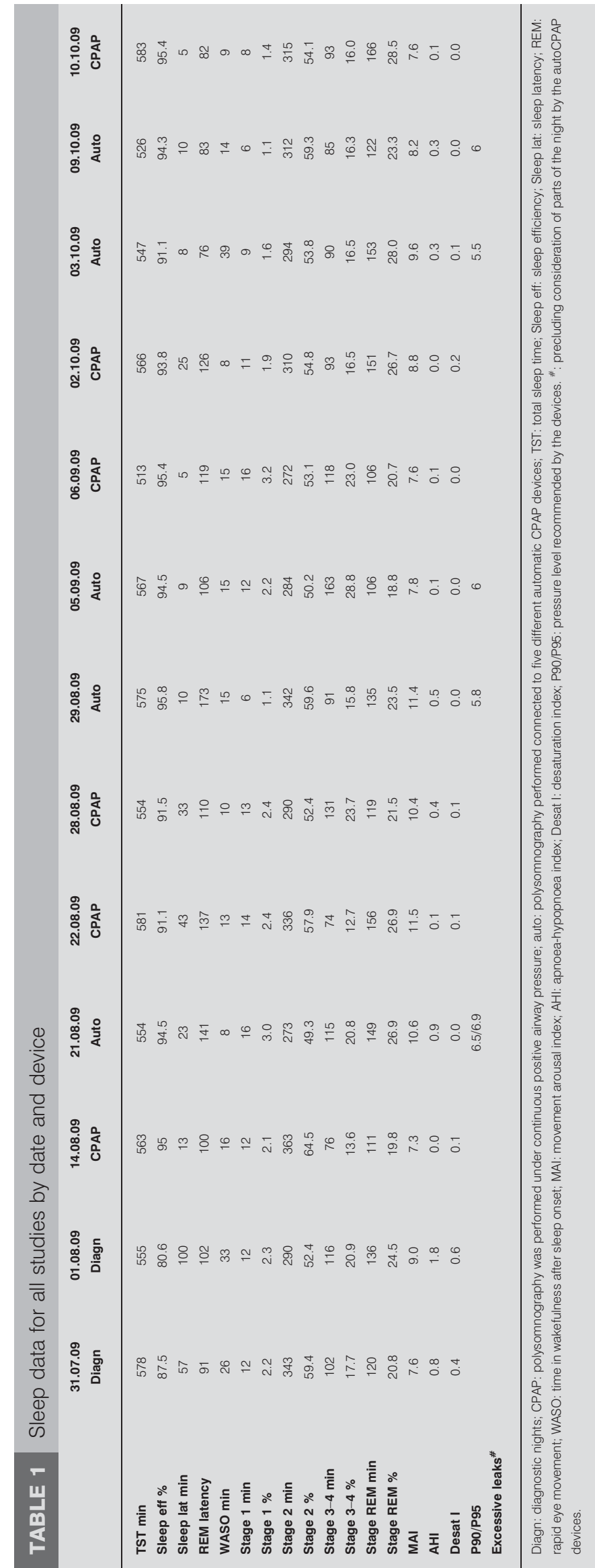


:

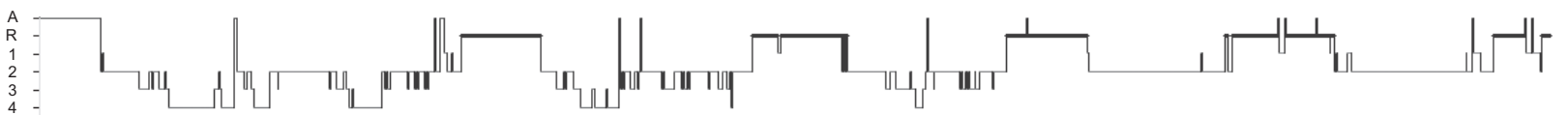

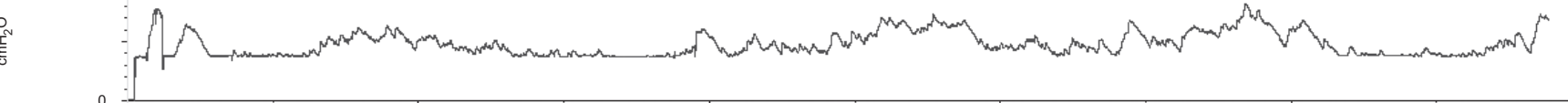

A
1
2
3
3
$M$
$M$
-
10

可

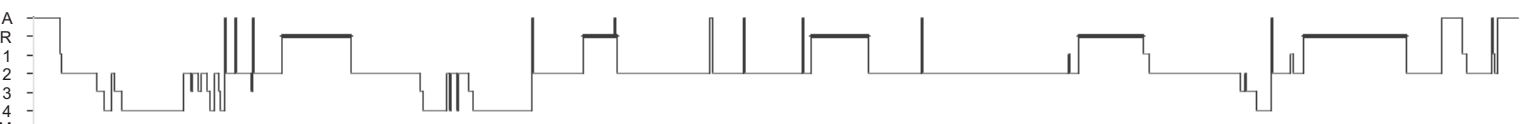




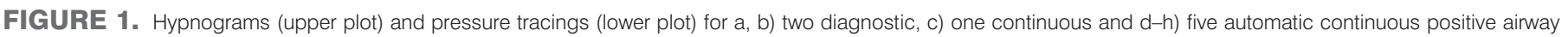

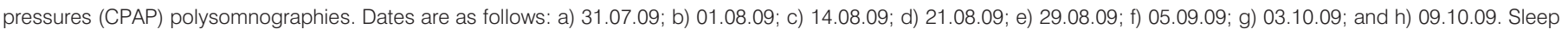

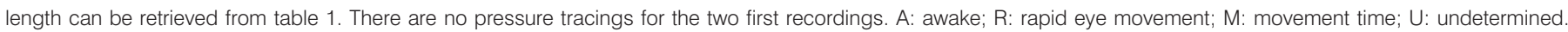

All autoCPAP devices reports recommended a pressure $>4 \mathrm{cmH}_{2} \mathrm{O}$ for long-term treatment (between 5.5 and 6.5 $\mathrm{cmH}_{2} \mathrm{O}$ ). All devices identified some abnormal breathing events. None of the devices rejected any part of the night due to excessive leaks.

We have found that the tested autoCPAP devices applied to a normal subject increased pressure above baseline during substantial parts of the night; that many of these increases were initiated either without any identifiable cause or after normal night events; that the pressure levels attained and the characteristics of the pressure increases varied greatly from one device to another; and that most of these increases did not disturb sleep. The pressure increases we observed were rather modest with maximal pressure remaining always below $10 \mathrm{cmH}_{2} \mathrm{O}$. The automatic reports produced by the devices recommended fixed pressures for long-term treatment 37.5$62.5 \%$ above the baseline value of $4 \mathrm{cmH}_{2} \mathrm{O}$.

It has previously been shown that $\sim 20 \%$ of events detected by an autoCPAP correspond to wakefulness and that $60 \%$ of clinical significant events were not detected [10]. Bench studies have shown that autoCPAP devices faced with standardised events react in very different ways. Some devices recognise apnoeas or hypopnoeas, but not all devices react by increasing pressure [7]. Our data confirm these previous findings but tested in a normal subject and show in addition that autoCPAP devices can increase pressure without reason, or in response to non-respiratory events (such as body position changes or spontaneous movement arousals).

We only studied one subject since autoCPAP devices have never been tried in normal subjects and because we believed it was not necessary to include more subjects to demonstrate that these devices overreact in the face of trivial events or even at random. The therapeutic pressure they recommend is thus partly unreliable and includes some level of error. Its actual magnitude and clinical importance remains to be determined and will require larger studies. Until these studies are performed, a dose of scepticism is necessary when autoCPAPs are used for titration and before conversion to a fixed therapeutic pressure. The assumption that all devices perform similarly should also be abandoned. Finally, our data show that autoCPAPs should not be used for diagnostic purposes.

In conclusion, we found that autoCPAP machines reacted in different ways and recommended different therapeutic levels of fixed pressure when applied to the same normal subject. These differences could have a clinical impact; a normal subject using the most sensitive devices could be wrongly diagnosed, or could be treated with higher pressures than needed. Detailed studies seem necessary to determine the optimal settings for each device for clinical use.

\section{G.B. Mwenge, M. Dury, P. Delguste and D. Rodenstein} Pneumology Dept and Center for Sleep Medicine, Cliniques Universitaires Saint-Luc, Université catholique de Louvain, Brussels, Belgium.

Correspondence: D. Rodenstein, Service de pneumologie, Cliniques Universitaires Saint-Luc, Av Hippocrate 10, 1200 Brussels, Belgium. E-mail: rodenstein@pneu.ucl.ac.be

Statement of Interest: A statement of interest for this study can be found at www.erj.ersjournals.com $/ \mathrm{site} / \mathrm{misc} /$ statements. xhtml

Clinical trial: This study is registered with Clinicaltrials.gov (NCT01064258).

Acknowledgements: The authors gratefully acknowledge the help of P. Stormacq and of the representatives of the five manufacturers who lent us the autoCPAP devices.

\section{REFERENCES}

1 Patil SP, Schneider H, Schwartz AR, et al. Adult obstructive sleep apnea: pathophysiology and diagnosis. Chest 2007; 132: 325-337.

2 Sullivan CE, Issa FG, Berthon-Jones $\mathrm{M}$, et al. Reversal of obstructive sleep apnoea by continuous positive airway pressure applied through the nares. Lancet 1981; 1: 862-865.

3 Berthon-Jones M. Feasibility of a self-titrating CPAP machine. Sleep 1993; 16: Suppl. 8, S120-S121.

4 Bradley PA, Mortimer IL, Douglas NJ. Comparison of polysomnography with ResCare Autoset in the diagnosis of the sleep apnea/ hypopnea syndrome. Thorax 1995; 50: 1201-1203.

5 Teschler H, Berthon-Jones M, Thompson AB, et al. Automated continuous positive airway pressure titration for obstructive sleep apnea syndrome. Am J Respir Crit Care Med 1996; 154: 734-740.

6 Teschler H, Wessendorf TE, Farhat AA, et al. Two months autoadjusting versus conventional nCPAP for obstructive sleep apnoea syndrome. Eur Respir J 2000; 15: 990-995.

7 Farre R, Montserrat JM, Rigau J, et al. Response of automatic continuous positive airway pressure devices to different sleep breathing patterns: a bench study. Am J Respir Crit Care Med 2002; 166: 469-473.

8 Pevernagie D, Masa JF, Meurice JC, et al. Treatment of obstructive sleep-disordered breathing with positive airway pressure systems. Eur Respir Rev 2007; 16: 125-131.

9 Collard P, Dury M, Delguste P, et al. Movement arousals and sleep-related disordered breathing in adults. Am J Respir Crit Care Med 1996; 154: 454-459.

10 Rees K, Wraith PK, Berthon-Jones M, et al. Detection of apnoeas, hypopnoeas and arousals by the AutoSet in the sleep apnoea/ hypopnoea syndrome. Eur Respir J 1998; 12: 764-769.

DOI: $10.1183 / 09031936.00139510$ 